surprising that only a few investigations have been carried out in this regard.

When an upward shift in magnitude of reward was introduced in Phase 2, no elation effects were observed in the 0-, 15-, or 30-sec delay conditions. The absence of an elation effect in the 0-sec delay condition provides additional support for the growing number of studies showing an absence of elation effects under similar circumstances. The fact that an elation effect was also not obtained in either the $15-\mathrm{sec}$ or the $30-\mathrm{sec}$ delay condition indicates that delay perse is not a sufficient condition for the occurrence of positive contrast when an upward shift in magnitude of reward is made along with delay. Since a temporary negative contrast effect resulting from a shift in delay was obtained in Phase 3 , the absence of a positive contrast effect in Phase 2 could be attributed to the fact that the control groups (12-15 and 12-30) did not experience a negative contrast effect based on a shift in delay, as apparently was the case in the study by Shanab et al (1969). However, more direct tests of this hypothesis are being considered.

\section{REFERENCES}

BOWER, G. H. A contrast effect in differential conditioning. Journal of Experimental Psychology, 1961, 62, 196-199.

DUNHAM, P. J. Contrasted conditions of reinforcement: A selective review. Psychological Bulletin, 1968, 69, 295-315.

HALPERN, J., SCHWARTZ, J. A., \& CHAPMAN, R. Simultaneous and successive contrast effects in human-probability learning. Joumal of Experimental Psychology, 1968, $77,581-586$.

LOGAN, F. A. Incentive. New Haven: Yale University Press, 1960.

SHANAB. M. E., SANDERS, R. \& PREMACK, D. Positive contrast in the runway obtained with delay of reward. Science, 1969, 164, 724-725.

\title{
Recent mating experience and olfactory preferences in androgenized female rats*
}

\author{
RICHARD T. ROBERTSON and RICHARD E. WHALEN \\ University of California at Irvine, Irvine, Calif. 92664
}

Neonatally androgenized female rats display a behavioral preference for the odor of sexually receptive female rats. This preference is not seen under conditions of low sexual arousal, but is evident after a brief mating session. The results are discussed in regard to the "masculinizing" effects of early androgen treatment.

Several recent studies have demonstrated that androgen treatment of the neonatal rat eliminates the display of female sexual receptivity in adulthood (Grady, Phoenix, \& Young, 1965; Harris \& Levine, 1965; Whalen \& Edwards, 1967). Androgen

\footnotetext{
*Supported by Research Grant HD-00893 to REW from the National Institute of Child Health and Human Development.
}

treatment in infancy does not, however, appear to increase the display of masculine sexual behavior. Whalen \& Edwards (1967) and Whalen, Edwards, Luttge, \& Robertson (1969) report no enhancement of male-type mounting behavior in females treated with testosterone at birth, as compared with control females. Thus, early androgen treatment produces an animal which is "less feminine" but not "more masculine," at least in terms of mating behavior.

Mating, however, has not been the only behavior shown to be under gonadal hormone control in the male rat. Sexually experienced males exhibit a preference for the odor of receptive females, while castrates and prepuberal males do not (LeMagnen, 1952; Carr, Loeb, \& Dissinger, 1965; Stern, 1970). Thus, behavioral preference for sex odors may be another index of masculinity in the rat. Since early androgen treatment could have masculinizing effects which are revealed in more subtle ways than in overt mating behavior, we have investigated the sex-odor preference of the neonatally androgenized female rat.

SUBJECTS AND PROCEDURES

Pregnant Sprague-Dawley rats were administered subcutaneous doses of $2 \mathrm{mg} /$ day of testosterone propionate (TP) ${ }^{1}$ in oil or oil alone on Days 16-20 of gestation. Female offspring from the TP-treated mothers $(N=10)$ received a single subcutaneous dose of $1 \mathrm{mg}$ TP $96 \mathrm{~h}$ after birth; at the same time the female offspring of the oil-treated mothers $(\mathrm{N}=8)$ were injected with oil. All Ss were ovariectomized at 60 days of age.

Starting at approximately 100 days of age all Ss were treated with progressively increasing doses of TP as follows: Week 1, 150 micrograms/day; Week 2, 300 micrograms/day; Week 3, 500 micrograms/day; Weeks 4 and 5 , 1,000 micrograms/day. Rats were tested on Days 5 and 7 of each week in a dimly lit room during the dark phase of a reversed light-dark cycle.

The odor-preference tests took place in an opaque white Plexiglas straight alley, $36 \times 5 \frac{11}{2} \times 6$ in., with a clear Plexiglas lid so the $O$ could view the $S$. The alley was marked off in four equally sized areas. Two goal boxes were separated from the alley by clear Plexiglas doors with holes drilled in them so the $S$ could see and smell, but not touch, the stimulus female. A female brought into behavioral estrus by exogenous hormones and an ovariectomized nontreated female, both anesthetized with Nembutal, served as stimuli and were placed in opposite goal boxes.

Ss, in a random order, were placed in the middle of the alley and allowed to move freely for a 5 -min period. The $O$ recorded the amount of time spent in each of the four areas of the straight alley. After the first preference test on Weeks 14 , Ss were given a $15-\mathrm{min}$ mating session with receptive females (see Whalen et al, 1969, for the results of mating tests). They were then given the second odor-preference test, similar to the first, except that the 


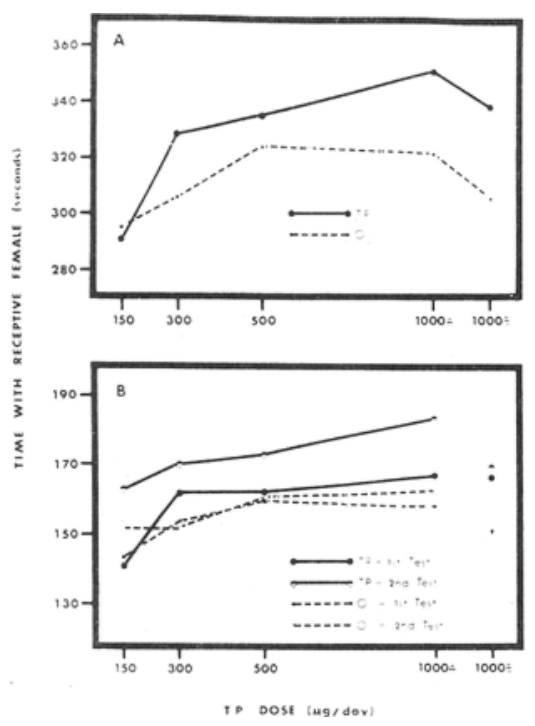

Fig. 1. Time spent with receptive female in odor preference tests. Ss were female rats treated neonatally with TP or oil, and given increasing doses of TP in adulthood. Dose of $1,000 \mathrm{micrograms} / \mathrm{day}$ was given for 2 weeks, with mating tests on 1 week $(1000 \mathrm{~A})$ and without mating tests on the other (1000B). (1A) Total time spent with receptive female in two 5-min tests. (1B) Time spent with receptive female for 5-min tests before (Test 1) and after (Test 2) a mating session.

receptive and nonreceptive stimulus females exchanged positions. On Week 5 , no between-test mating session was given. Care was taken to see that the runway was clean after each $\mathrm{S}$ had been tested.

The rats spent very little time in the two center areas, primarily being scored as in them only while going from one end of the box to the other. So, for convenience, the center areas were each combined with their respective endbox areas for the analysis of time spent with the receptive female. Mean scores from the 2 test days at each hormone dose were used for the analysis. RESULTS AND DISCUSSION

Figure la compares the preference for the goalbox containing the receptive female for each group at each dosage level. The analysis of variance for repeated measures demonstrated that the androgenized females spent significantly more time with the receptive females than did controls $(F=12.61, \mathrm{df}=1,16, \mathrm{p}<.01)$ and that TP dose was also a significant factor $(F=3.59, \quad d f=4,68, \quad p<.05)$. Interaction effects were not significant $(F=1.19, \quad \mathrm{df}=4,68)$. These "odor preference" data indicate that, in contrast to results from tests of mating behavior, the early androgen treatments do enhance the display of male behavior in the female rat.
More recent data from Carr, Krames, \& Costanzo (1970) have shown that the behavior displayed in olfactory preference tests is influenced by the immediate prior mating activities of the $S$. These results prompted a reexamination of our data, as in Weeks $1-4$ the two preference tests had been separated by a mating session.

Figure 1B presents odor preference scores for Test 1. (before mating) and Test 2 (after mating) for each group. Analysis of variance indicates that while the two groups did not differ on Test 1 $(F=.92, \quad d f=1.16)$, the differences between the first and second tests are significantly greater in the androgenized than in the control Ss $(F=5.03, \mathrm{df}=1,16$, $\mathrm{p}<.05$ ). That is to say, the androgenized females exhibited a greater preference for the estrous than for the nonestrous stimulus female after a mating test than before a mating test, while the nonandrogenized females showed no change in preference as a function of the interpolated mating test. The significant difference between the two groups shown in Fig. 1 A, then, can be accounted for by the increased preference displayed by the androgenized females after the mating session. The effect of increasing doses of TP was not significant in this analysis $(\mathrm{F}=2.23, \mathrm{df}=3,48)$.

The importance of the between-test mating session was also demonstrated in Week 5, when no mating test was interposed between the preference tests. On that week, with no mating session, there were no differences between the first and second tests for either group $(F=.21$, $\mathrm{df}=1,16)$.

The lack of differences between the two groups on the initial test indicates that the early androgen treatment did not have a general masculinizing effect on the females, at least while in what might be called a state of low sexual arousal (Whalen, 1966). After $15 \mathrm{~min}$ of mating, however, the androgenized females exhibited a significantly greater increase in the preference of odors from the receptive females. These data could be interpreted as meaning that the androgenized females were actually more masculine, but that this is a sensitive difference and may only show up under conditions of high sexual arousal. If display of increased masculinity were observable only under conditions of high arousal, however, it would certainly be expected during the mating tests. This is not the case (Whalen \& Edwards, 1967; Whalen et al, 1969), although the possibility remains that the odor preference test is a more sensitive measure of "masculinity" than mating behavior.

On the other hand, these observations may not be due to enhanced masculine motivation. Although the two groups did not differ in frequency of mounting in the mating tests, the androgenized females achieved twice as many intromissions (Whalen et al, 1969), probably due to increased size of the phallus (Grady et al, 1965; Whalen \& Edwards, 1967). Thus the increase in preference after mating may simply occur because the mating experience was more rewarding in terms of sensory input to the androgenized females, and a temporary association formed between mating and the odor characteristics of the estrous female. Stern (1970), however, has recently shown that mounting experience without intromission is sufficient to maintain odor preferences in the male rat.

That the androgenized females exhibited a preference greater than controls without the mating tests on Week $5(\mathrm{~F}=11.14$, df $=1,16, p<.01$ ) need not detract from this hypothesis. The long series of mating and preference tests prior to these final preference tests could easily have had some residual effect. Certainly the lack of differences between the two groups on the first tests on Weeks $1 \mathcal{4}$ suggests no general increase in masculinity.

\section{REFERENCES}

CARR, W. J., KRAMES, L., \& COSTANZO, D. J, Previous sexual experience and olfactory preference for novel versus original sex partners in rats. Journal of Comparative \& Physiological Psychology, 1970, 71, 216-222.

CARR, W. J., LOEB, L. S., \& DISSINGER, M. L. Responses of rats to sex odors. Journal of Comparative \& Physiological Psychology, $1965,59,370-377$.

GRADY, K. L., PHOENIX, C. H., \& YOUNG, W. C. Role of the developing rat testis in differentiation of the neural tissues mediating mating behavior. Joumal of Comparative \& Physiological Psychology, 1965, 59, 176-182.

HARRIS, G. W., \& LEVINE, S. Sexual differentiation of the brain and its experimental control. Journal of Physiology, $1965,181,379-400$.

LeMAGNEN, J. Les phenomenes olfacto-sexuels chez le rat blanc. Archives de Science Physiologiques, 1952, 6, 295-332.

STERN, J. J. Responses of male rats to sex odors. Physiology \& Behavior, 1970, 5, 519-524.

WHALEN, R. E. Sexual motivation. Psychological Review, 1966, 73, 151-163.

WHALEN, R. E., \& EDWARDS, D. A. Hormonal determinants of the development of masculine and feminine behavior in male and female rats. Anatomical Record, 1967, 157, 173-180.

WHALEN, R. E., EDWARDS, D. A., LUTTGE, W. G., \& ROBERTSON, R. T. Early androgen treatment and male sexual behavior in female rats. Physiology \& Behavior, 1969, 4, 33-39. NOTE

1. The hormones were generously supplied by P. Perlman of the Schering Corporation. 